\title{
Metastases of malignant melanoma to stomach
}

\author{
Ufuk Barıs Kuzu${ }^{1}$, Nuretdin Suna², Hale Gokcan ${ }^{1}$, Samir Abdullazade ${ }^{3}$, Erkin Öztas ${ }^{1}$, Bulent Odemis ${ }^{1}$ \\ ${ }^{1}$ Department of Gastroenterology, Turkiye Yuksek Ihtisas Training and Research Hospital, Ankara, Turkey \\ 2Department of Gastroenterology, Muş State Hospital, Muş, Turkey \\ ${ }^{3}$ Department of Pathology, Muş State Hospital, Muş, Turkey
}

Address for correspondence: Ufuk Barıs Kuzu MD, Department of Gastroenterology, Turkiye Yuksek Ihtisas Training and Research Hospital, Atatürk Bulvarı Kızılay Sokak, No: 4, Sıhhiye, 06100 Ankara, Turkey, phone: +90 312 3061334, fax: +90 3123124120 ,

e-mail: ubarisk@gmail.com

Malignant melanoma (MM) is one of the most common tumours that metastasises to the gastrointestinal (GI) tract. The small intestines are the most common site for this metastasis; however, the stomach is also a rare site $[1,2]$.

A 58-year-old male patient applied to the gastroenterology outpatient clinic with nausea and epigastric pain. He had a history of localised cutaneous MM excision from the right thigh 5 years earlier. Lab work showed no significant abnormality on blood biochemistry. His esophagogastroduodenoscopy showed multiple, black-pigmented lesions of various sizes (Figure 1). A biopsy from these lesions revealed MM metastasis (Figure 2).

Malignant melanoma may involve the GI tract as a metastatic lesion, or rarely as a primary tumour. Gastrointestinal tract metastasis can be seen synchronous with the primary tumour, or as a recurrent tumour years later [1, 2]. Gastric involvement may be seen as a black-pigmented ulcer or as diffusely spread black-pigmented lesions, as in our case [3]. However, a histopathological exam may not differentiate a primary lesion from a metastatic one [4]. Immunohistochemistry should be employed to prove MM with markers such as HMB-45 and S100 [5]. Treatment options for metastatic involvement of the Gl tract with $M M$ are surgery, chemotherapy, immunotherapy, and palliative therapy. Only surgery is reported to increase survival to some extent [1].

As a result, because MM metastasis may show up years later, we suggest screening of GI tract in MM patients if there is the presence of Gl symptoms.

\section{Conflict of interest}

The authors declare no conflict of interest.

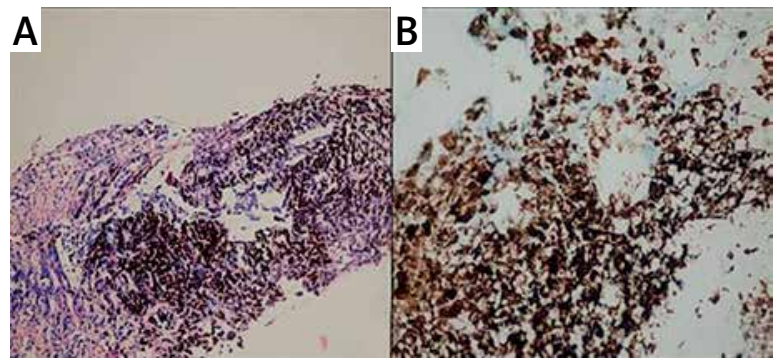

Figure 2. A - Gastric mucosa with evident black pigmentation (haematoxylin and eosin stain, 100x). B - HMB-45 positivity in neoplastic cells (immunohistochemical stain, 200x) 


\section{References}

1. Schuchter LM, Green R, Fraker D. Primary and metastatic diseases in malignant melanoma of the gastrointestinal tract. Curr Opin Oncol 2000; 12: 181-5.

2. Liang KV, Sanderson SO, Nowakowski GS, Arora AS. Metastatic malignant melanoma of the gastrointestinal tract. Mayo Clin Proc 2006; 81: 511-6.

3. Katsanos KH, Tsianos VE, Tsianos EV. Metastatic melanoma in stomach and large bowel. Ann Gastroenterol 2010; 23: 322-4.

4. Kotteas EA, Adamopoulos A, Drogitis PD, et al. Gastrointestinal bleeding as initial presentation of melanoma of unknown primary origin: report of a case and review of the literature. In Vivo 2009; 23: 487-9.

5. Clemmensen OJ, Fenger C. Melanocytes in the anal canal epithelium. Histopathology 1991; 18: 237-41.

Received: 8.04.2015

Accepted: 18.05.2015 